\title{
CONF- $970834--6$
}

\section{IRRADIATION-INDUCED MICROSTRUCTURAL CHANGES IN ALLOY X-750}

\section{E. A. Kenik}

Metals and Ceramics Division, Oak Ridge National Laboratory, Oak Ridge, TN 37831-6376

Alloy X-750 is a $\gamma^{\prime}$-strengthened Ni-base alloy that is often used in nuclear power systems for its excellent corrosion resistance and good mechanical properties.' However, radiation-induced segregation (RIS) and irradiation-assisted stress corrosion cracking (IASCC) can occur under neutron irradiation. ${ }^{2}$ The present study examines the microstructure and composition profiles in a heat of Alloy X-750 before and after neutron irradiation. ${ }^{3}$

The material was in the $\mathrm{HTH}$ commercial heat treatment ( $\mathrm{h}$ at $1121^{\circ} \mathrm{C}+$ air cooling $+20 \mathrm{~h}$ at $704^{\circ} \mathrm{C}$ ). Specimens were prepared from both control material and material irradiated at $360^{\circ} \mathrm{C}$ to a fluence of $2.3 \times 10^{20} \mathrm{n} / \mathrm{cm}^{2}$ ( $\mathrm{E}>1 \mathrm{MeV}$ ), which was estimated to produce $\sim 0.4$ displacements per atom. High spatial resolution analytical electron microscopy was performed in a Philips EM400T/FEG operated in the STEM mode with a probe diameter of $\sim 1.4 \mathrm{~nm}$ (FWHM). Composition profiles were acquired in two different ways: all energy dispersive X-ray spectrometry (EDS) and some parallel-detection electron energy-loss spectrometry (PEELS) profiles were acquired as individual spot analyses, whereas the majority of the PEELS profiles were acquired as spectrum lines with $\sim 10 \mathrm{~s}$ acquisition times per point. The quoted compositions are as measured (wt\%); no deconvolution for the effect of the excited volume was performed.

The control material exhibited a complex, multiphase microstructure including fine $(\sim 20 \mathrm{~nm})$ intragranular $\gamma^{\prime}$ precipitates along with several intergranular phases. Some regions of intergranular precipitation exhibited $\mathrm{M}_{23} \mathrm{C}_{6}$ and $\gamma^{\prime}$ precipitates (e.g., Fig. 1), whereas others exhibited $M_{23} C_{6}$ and a co-precipitate containing both $M_{23} C_{6}$ and a structurally-related phase (Fig. 2). This precipitate had overall electron diffraction patterns consistent with the $\mathrm{M}_{23} \mathrm{C}_{6}$ structure. Some regions exhibited a composition ( $>85 \mathrm{Cr}, \sim 3 \mathrm{Fe}, \sim 7 \mathrm{Ni}$ ) consistent with $\mathrm{M}_{23} \mathrm{C}_{6}$, whereas other regions exhibited a distinctly different composition $(\sim 7 \mathrm{Ti}, \sim 2 \mathrm{Fe}, \sim 2 \mathrm{Cr}, \sim 2 \mathrm{Nb}$, and $>80 \mathrm{Ni})$. Convergent beam electron diffraction indicated that the $\mathrm{Cr}$-rich and Ni-rich regions exhibited very similar, parallel-oriented diffraction patterns. PEELS light element analysis indicated that the chromium-rich phase contains carbon with little or no boron; whereas the nickel-enriched phase contains boron with little or no carbon. This analysis identified the Ni,Ti-enriched phase as the $\tau$ boride $\left(\mathrm{M}_{23} \mathrm{~B}_{6}\right)$ which is isostructural with $\mathrm{M}_{23} \mathrm{C}_{6}$. The structurally similar boride forms cube-on-cube with the $\mathrm{M}_{23} \mathrm{C}_{6}$ and appears as a single, homogeneous precipitate under most diffracting conditions. However, slight defocussing of the image permits the different regions to be visualized in the TEM mode (inset in Fig. 2), where the $\tau$ phase appears mottled and the $\mathrm{M}_{23} \mathrm{C}_{6}$ phase exhibits more uniform contrast. This contrast difference may be a surface-related effect associated with electropolishing.

Composition profiles were measured in the control material at precipitate-free sections of grain boundaries and at intergranular precipitate interfaces. An apparently precipitate-free grain boundary exhibited a narrow $(<10 \mathrm{~nm})$ region depleted to $\sim 7 \% \mathrm{Cr}$ and enriched to $\sim 6 \% \mathrm{Ti}$ (PEELS - Fig. 3). X-ray microanalysis on a similar boundary indicated similar $\mathrm{Cr}$ depletion and enrichment of $\mathrm{Al}$ and $\mathrm{Nb}$, as well as $\mathrm{Ti}$. This behavior was attributed to the undetected presence of a thin precipitate enriched in these three elements (i.e., $\gamma^{\prime}$ phase). This assumption was confirmed by the presence of other precipitate-free grain boundaries that exhibited Ti levels $<1 \%$. The average $\mathrm{Cr}$ level for such boundaries was measured as $13.3 \%$ (EDS) and $15.8 \%$ (PEELS).

Faulted dislocation loops $(5-25 \mathrm{~nm})$ and isolated cavities $(1.5-8 \mathrm{~nm})$ were present in the irradiated matrix. Depletion of $\mathrm{Cr}$ and $\mathrm{Fe}, \mathrm{Ni}$ enrichment and no $\mathrm{Ti}$ enrichment were observed for a precipitate-free grain boundary in the irradiated material (Fig .4). The average $\mathrm{Cr}$ level for such low-Ti grain boundaries was measured as $11.0 \%$ (EDS) and $11.5 \%$ (PEELS). The change in minimum chromium level at non- $\mathrm{M}_{23} \mathrm{C}_{6}$ interfaces for the control and the irradiated materials as measured by PEELS is $4.3 \mathrm{wt} \%$, larger than measured by EDS ( $2.3 \mathrm{wt} \%)$. This difference may in part reflect the better spatial resolution of PEELS because of the reduced influence of beam broadening. Further high spatial resolution AEM will be required to clarify the role of RIS in IASCC of Alloy X-750. ${ }^{4}$

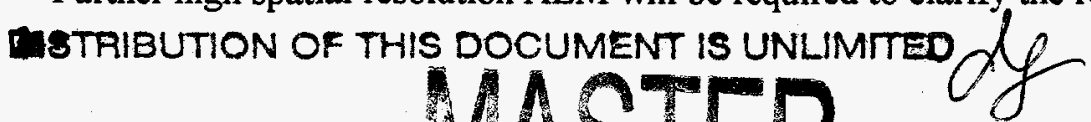

"The submitted manuscript has been authored by a contractor of the U.S. Government under contract No. DE-AC05-960P22464. Accordingly, the U.S. 


\section{DISCLAIMER}

This report was prepared as an account of work sponsored by an agency of the United States Government. Neither the United States Government nor any agency thereof, nor any of their employees, makes any warranty, express or implied, or assumes any legal liability or responsibility for the accuracy, completeness, or usefulness of any information, apparatus, product, or process disclosed, or represents that its use would not infringe privately owned rights. Reference herein to any specific commercial product, process, or service by trade name, trademark, manufacturer, or otherwise does not necessarily constitute or imply its endorsement, recommendation, or favoring by the United States Government or any agency thereof. The views and opinions of authors expressed herein do not necessarily state or reflect those of the United States Government or any agency thereof. 


\section{DISCLAMIER}

Portions of this document may be illegible in electronic image products. Images are produced from the best available original document. 


\section{REFERENCES}

1. A.R. Mcllree, in Environmental Degradation of Materials in Nuclear Power Systems - Water Reactors (NACE, Houston, TX 1984), 838.

2. R. Bajaj, W.J. Mills, M.R. Lebo, B.Z. Hyatt, and M.G. Burke, in Environmental Degradation of Materials in Nuclear Power Systems - Water Reactors (NACE, Houston, TX 1995) 1093.

3. E.A. Kenik, in Microstructure Evolution During Irradiation, 1996 MRS Symposia Proceedings, Materials Research Society, Pittsburgh (In Press).

4. Research at Oak Ridge National Laboratory SHaRE User Facility supported in part by Division of Materials Sciences, U.S. Department of Energy under contract DE-AC05-96OR22464 with Lockheed Martin Energy Research Corporation.
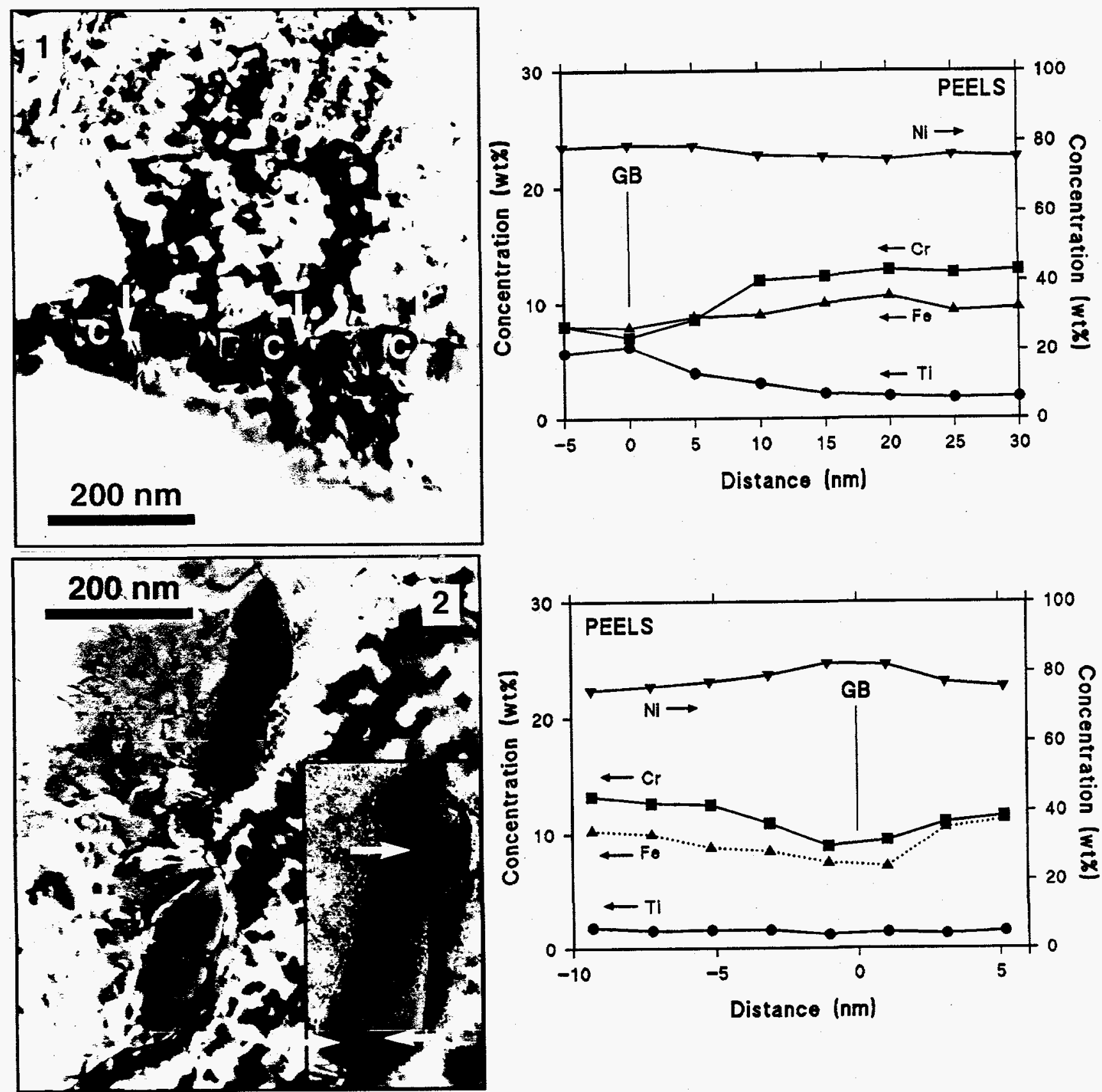

FIG. 1 Grain boundary in control material exhibiting predominantly $\mathrm{M}_{23} \mathrm{C}_{6}(C)$ with some $\gamma^{\prime}$ interspersed (arrowed). FIG. 2 Grain boundary in control material with mixed particles of $M_{23} C_{6}$ carbide/ $\tau\left(M_{23} B_{6}\right)$ boride $\left(M_{23} C_{6}\right.$ arrowed). FIG. 3 Composition profile (PEELS) at an apparently precipitate-free grain boundary in the irradiated material. FIG. 4 Composition profile (PEELS) at a precipitate-free grain boundary in the irradiated material. 